\title{
Automated quantification of Ki-67 proliferative index of excised neuroendocrine tumors of the lung
}

Sandy Z Liu, Paul N Staats, Lindsay Goicochea, Borislav A Alexiev, Nirav Shah, Renee Dixon and Allen P Burke*

\begin{abstract}
Background: The histopathologic distinction between typical carcinoid (TC) and atypical carcinoid (AC) of the lung is based largely on mitotic index. Ki-67 may aid in separation of these tumors, as well as the distinction from large cell neuroendocrine carcinoma (LCNEC).

Methods: We identified 55 surgically resected primary neuroendocrine lung tumors (39 TC, 7 AC, 9 LCNEC) based on mitotic rate and histologic features. Ki-67 proliferative index based on automated image analysis, tumor necrosis, nodal metastases, local or distant recurrence, and survival were compared across groups.

Results: The mean mitotic count and Ki-67 index for TC, AC, and LCNEC were 0.1 and 2.3\%, 3.4 and 16.8\%, and 56.1 and $81.3 \%$ respectively. The Ki-67 index did not overlap among groups, with ranges of 0-6.7\% for TC, 9.9-25.7\% for AC, and 63.2-91.9\% for LCNEC. Nodal metastases were identified in 4/39 (10\%) TC, 2/7 (22\%) AC, and 2/8 (25\%) LCNEC. There was no survival difference between TC and AC, but there was a significant survival difference between LCNEC and TC and AC combined $(p<0.001)$. There was a step-wise increase in disease free survival with tumor grade: no TC recurred, 2/7 AC recurred or progressed (median interval 35.5 months), and all LCNEC recurred or progressed (median interval 10.1 months). No patient with TC or AC died of disease, compared to 7/8 LCNEC with follow-up data.

Conclusions: We conclude that Ki-67 index is a useful diagnostic marker for neuroendocrine tumors, with 7\% a divider between AC and TC, and 50\% a divider between LCNEC and AC. LCNEC is biologically different from AC and TC, with a much more aggressive course, and a high Ki-67 index.
\end{abstract}

Virtual Slides: The virtual slide(s) for this article can be found here: http://www.diagnosticpathology.diagnomx.eu/ vs/13000_2014_174

Keywords: Proliferation index, MIB-1, Ki-67, Carcinoid tumor, Neuroendocrine carcinoma, Lung neoplasms, Pathology

\section{Background}

Neuroendocrine tumors of the lung account for approximately $20-25 \%$ of primary lung tumors [1]. The most common type is small cell carcinoma, accounting for $15-20 \%$, followed by large cell neuroendocrine carcinoma (LCNEC) ( 3\%), typical carcinoid (TC), and atypical carcinoid (AC) tumors ( 1-2\%). Other than small cell carcinomas, neuroendocrine tumors are typically initially treated by surgical excision. The distinction between these four tumor types is based on histologic features, mitotic index,

\footnotetext{
* Correspondence: Allen.burke@gmail.com

From the Departments of Pathology and Internal Medicine, University of Maryland, 22 S. Greene St, Baltimore 21201, USA
}

and presence or absence of necrosis [1,2]. Of these features, mitotic figures are particularly important in separating AC from TC (0-1 mitotic figures in 10 high-power microscopic fields (HPF) for TC, $1-10$ mitotic figures/10 $\mathrm{HPF}$ for $\mathrm{AC}$, and $>10 / 10$ mitotic figures $/ 10 \mathrm{HPF}$ for LCNEC).

Despite diagnostic criteria, inter-observer variability exists between typical and atypical carcinoid tumors [3,4]. Furthermore, diagnostic challenges can occur in a biopsy due to limited sampling or poor specimen handling (crush artifact) [5]. A distinction is important because of the different prognosis and treatment of carcinoid tumors vs. high-grade neuroendocrine carcinomas [6,7]. Several 
studies have shown a correlation between a high Ki-67 and a poorer prognosis [8-14]. Ki-67 has been shown to be more reliable and reproducible in distinguishing TC from $\mathrm{AC}$ than histology [3]. Additionally, a very high Ki-67 index can help distinguish LCNEC from AC when classification is doubt.

While previous investigations have correlated clinicopathologic characteristics and Ki-67 index in carcinoid tumors, relatively few studies have studied the spectrum of TC, AC, and LCNEC and provided diagnostic numeric criteria using Ki-67 similar to mitotic index. The purpose of this study is to correlate Ki-67 mitotic index calculated by digital image analysis with clinicopathologic variables of non-small cell neuroendocrine tumors and to provide specific ranges of proliferative index for diagnostic use.

\section{Methods}

\section{Study population}

A search of electronic pathology database with the key words "carcinoid", "large cell neuroendocrine", and "neuroendocrine" of surgically resected lung tumors (wedge resection, lobectomy, pneumonectomy, airway resection) from January 2003 to December 2014, inclusive, revealed a total of 62 cases originally diagnosed as primary nonsmall cell neuroendocrine tumors. The study only included resection specimens; no biopsies were included. Secondary, recurrent, and metastatic tumors were also excluded. One tumor originally diagnosed as "poorly differentiated adenocarcinoma with neuroendocrine features" was reclassified as large cell neuroendocrine tumor based on the most recent World Health Organization criteria. One tumor originally diagnosed as "high grade neuroendocrine tumor" was reclassified as small cell carcinoma and excluded. Six tumors were excluded because of lack of histological material.

\section{Pathology and histological classification}

All cases were reviewed by at least 2 study pathologists to confirm their classification (ABP, SZL) based on the current WHO criteria for lung neuroendocrine tumors. TC was defined as well-differentiated neuroendocrine tumor with 0-1 mitoses/10 HPF, and without necrosis. ACs were distinguished by $2-10$ mitoses/10 HPF and/or focal necrosis. LCNECs had $>10$ mitotic figures in 10 HPF, usually with large areas of necrosis; showed neuroendocrine morphology (nuclear palisading with nests, rosette-like, or ribbons of cells); had prominent nucleoli and cytoplasm unlike small cell carcinoma; and showed immunohistochemical evidence of neuroendocrine differentiation (diffuse staining for either synaptophysin, chromogranin, or CD56 [15]. All tumors stained positive for at least one of three neuroendocrine markers: synaptophysin, chromogranin, or CD56.
The tumor size was obtained from the gross description in the surgical pathology laboratory. The tumor location was obtained from clinical and radiological information. Immunohistochemical staining was performed using an automated immunostainer (BenchMark, Ventana, Tucson, AZ) and Ultraview universal indirect biotin-free $\mathrm{DAB}$ detection kit. The following neuroendocrine and proliferative immunohistochemical markers were used: mouse monoclonal synaptophysin (Ventana), mouse monoclonal chromogranin-A (Ventana), mouse monoclonal CD56 (Ventana), and rabbit monoclonal Ki-67 (clone 30-9, Ventana).

\section{Mitotic count and Ki-67 proliferative index}

The mitotic activity was manually quantitated in the most cellular areas on whole-slide images scanned using the Aperio imaging system (Leica Biosystems, Buffalo Grove, IL); four 40x high power fields were calibrated as $1 \mathrm{~mm}^{2}$. The mitotic count was performed according to the method recommended in the $7^{\text {th }}$ edition of the AJCC Cancer Staging Manual: enumerate mitoses in the most mitotically active area ("hot spot") and then extend mitotic count to adjacent contiguous fields. If no mitotic activity is evident, random representative tumor fields are scanned for mitoses.

The Ki-67 proliferative index (PI) was performed blinded to any knowledge of mitotic counts and was quantitated using a validated nuclear algorithm (Aperio, Leica Biosystems, Buffalo Grove, IL), where slides were scanned at 20x magnification using the Aperio Scanscope Console and the images were analyzed using ImageScope Nuclear v9 algorithm software that reports the total number of nuclei counted and the percentage of positive cell nuclei. The Ki-67 digital image analysis had been previously validated for clinical and research use by comparing Aperio-generated results with scores using the Chromovision ACIS system (which had, in turn, been previously validated against manual Ki-67 counts) performed on the same slides of breast cancers. In brief, digital image analysis was completed twice for each test case using the Aperio Imagescope algorithm, and the outputs were then averaged and compared to the Chromovision ACIS results, which yielded the recommended acceptable level of agreement [16]. In our study, digital image analysis was executed by manually annotating at least three representative non-necrotic tumor fields which together contained at least total 2000 cells (or all tumor cells if less than 2000) in which automated analysis was to be performed. Positive staining was defined as faint nuclear positivity or greater $(1+)$. Care was taken to exclude fields containing substantial numbers of non-tumor cells, such as endothelial cells and intratumoral lymphocytes, and non-tumor cells were further excluded by calibrating the algorithm thresholds for nuclear size ( $>10 \mathrm{um}$ ), 
nuclear radius, nuclear roundness, and curvature so as to omit non-neoplastic cells. Limitation of scoring to tumor cells was verified through visual review of the marked-up digital images and the corresponding H\&Estained scanned slide.

\section{Statistical analysis}

All statistical analyses were performed using JMP 10.0 statistical software (SAS, USA). ANOVA analysis was performed between histological group (TC, AC, and LCNEC) and Ki-67 index. Fisher's two-sided exact test was used to analyze categorical data (race, smoking, gender, necrosis). Overall survival was calculated from the date of pathological diagnosis to time of death or last follow-up, and disease free survival was calculated from date of pathological diagnosis to time of last clinical evidence of recurrence, progression, or death. Overall survival curves and significance of survival and disease free survival distributions were generated using Kaplan-Meier and Log-Rank method. All p-values were two-sided. Multivariate survival fit was calculated by the Weibull parametric test.

\section{Results}

\section{Patient population}

There were a total of 55 lung neuroendocrine tumors: $39 \mathrm{TC}, 7 \mathrm{AC}$, and 9 LCNEC. In three patients, the neuroendocrine tumor was found incidentally: one TC discovered at wedge resection for presumed metastatic hepatocellular carcinoma, one TC discovered at pulmonary explant for emphysema, and one synchronous TC discovered at lobectomy for lung adenocarcinoma. There were a total of 41 females and 14 males (3:1 ratio),

\section{Clinical features}

Clinical characteristics are summarized in Table 1. All patients with LCNEC were smokers compared to 18 of 37 patients with TC or AC $(49 \%)(\mathrm{p}=0.0050$, Fisher's exact test, two-sided). There was a strong association with

Table 1 Pathological characteristics

\begin{tabular}{|c|c|c|c|c|}
\hline & All tumors & Typical & Atypical & Large cell \\
\hline Mitotic count $\left({ }^{\#} / 10 \mathrm{HPF}\right)^{\ddagger}$ & $10.4 \pm 1.5$ & $0.1 \pm 0.2$ & $3.4 \pm 2.1$ & $56.1 \pm 17.0$ \\
\hline Range & $0-79$ & $0-1$ & $2-8$ & $25-73$ \\
\hline Ki-67 index \pm SD $(\%)^{\ddagger}$ & $17.0 \pm 29.4$ & $2.3 \pm 1.8$ & $16.8 \pm 7.7$ & $81.3 \pm 9.9$ \\
\hline Range (\%) & $0-91.9$ & $0-6.7$ & $9.9-25.7$ & $63.2-91.9$ \\
\hline \multicolumn{5}{|l|}{ Presence of necrosis $\#$} \\
\hline Absent & $43(78 \%)$ & $39(0 \%)$ & $4(57 \%)$ & $0(0 \%)$ \\
\hline Present & $12(22 \%)$ & $0(100 \%)$ & $3(43 \%)$ & $9(100 \%)$ \\
\hline \multicolumn{5}{|l|}{ Presence of LVI } \\
\hline Absent & $43(78 \%)$ & $33(85 \%)$ & $5(71 \%)$ & $5(56 \%)$ \\
\hline Present & $12(22 \%)$ & $6(15 \%)$ & $2(29 \%)$ & $4(44 \%)$ \\
\hline \multicolumn{5}{|l|}{ Presence of perineural invasion } \\
\hline Absent & $48(87 \%)$ & $36(92 \%)$ & $7(100 \%)$ & $5(56 \%)$ \\
\hline Present & $7(13 \%)$ & $3(8 \%)$ & $0(0 \%)$ & $4(44 \%)$ \\
\hline \multicolumn{5}{|l|}{ Spindle histology } \\
\hline Absent & $48(87 \%)$ & $32(82 \%)$ & $5(71 \%)$ & $9(100 \%)$ \\
\hline Present & $7(13 \%)$ & $7(18 \%)$ & $2(29 \%)$ & $0(0 \%)$ \\
\hline \multicolumn{5}{|l|}{ Osseous metaplasia } \\
\hline Absent & 49 (89\%) & $34(87 \%)$ & $6(86 \%)$ & $9(100 \%)$ \\
\hline Present & $6(11 \%)$ & $5(13 \%)$ & $1(14 \%)$ & $0(0 \%)$ \\
\hline \multicolumn{5}{|l|}{ Original pathological diagnosis } \\
\hline Typical carcinoid & 40 & 36 & 4 & 0 \\
\hline Atypical carcinoid & 8 & 3 & 3 & 2 \\
\hline Large cell neuroendocrine & 4 & 0 & 0 & 4 \\
\hline Small cell carcinoma & 2 & 0 & 0 & 2 \\
\hline Poorly differentiated NSCLC & 1 & 0 & 0 & 1 \\
\hline
\end{tabular}

${ }^{\ddagger} \mathrm{p}<0.0001$, ANOVA, across all groups.

\# $\mathrm{p}<0.0001$, Fisher's exact test, comparing large cell NE vs. typical carcinoid.

${ }^{\#} p=0.0192$, Fisher's exact test, comparing large cell NE vs. atypical carcinoid.

$\# \mathrm{p}<0.0001$, Fisher's exact test, comparing atypical carcinoid vs. typical carcinoid. 
LCNEC and black race, compared to TC and AC ( $\mathrm{p}=$ 0.0005 , Fisher's exact test, two-sided). Fifty-three tumors were M0 and 2 tumors (one LCNEC, one AC) were M1 at time of presentation. There was no association between tumor size, location, TNM stage, gender, and age with tumor histology.

\section{Histological features}

The histological characteristics are summarized in Table 2. The ranges for mitotic count did not overlap by definition (Figures 1, 2 and 3). In addition the Ki-67 index for TC, AC, and LCNEC did not overlap (Figure 4). The mean mitotic count and Ki-67 index across all groups were statistically different (ANOVA, $\mathrm{p}<0.0001$ ). Among all tumors, in aggregate, there was a strong correlation between mitotic count and Ki-67 PI by linear regression $\left(R^{2}=0.90, p<\right.$ 0.0001 ) (Figure 5). Necrosis, as expected, showed an increase in incidence with higher grade (Table 2). There was no significant difference in lymphovascular and perineural invasion with increasing tumor grade (Table 2). Spindled histology and osseous metaplasia were observed only in $\mathrm{TC}$ and $\mathrm{AC}$.

\section{Survival and progression free survival analysis}

Survival and progression free survival analysis are summarized in Table 3. Available clinical information for disease status at last follow-up was available in 47 of 55 cases, 33 of $39 \mathrm{TC}, 7$ of $7 \mathrm{AC}$, and 8 of 9 LCNEC. At the end of the study, 11 patients were deceased: 3 with TC, 1 with AC, and 7 with LCNEC. Three patients with TC died of other causes, two of which were known: one from metastatic hepatocellular carcinoma and one from recurrent pulmonary adenocarcinoma. There was no disease recurrence in TC $(0 / 33)$. Two patients with AC had progression of disease: one with metastatic nodal disease and one with distant metastases. The deceased patient with $\mathrm{AC}$ had metastatic disease at initial presentation, and died from disease 2.5 months after diagnosis. Seven patients with LCNEC died of disease, one patient is alive with recurrent disease,, and one patient did not have sufficient follow-up. No survival difference was observed between TC and AC. (Figure 6A). There was a step-wise decrease in disease free survival with increasing tumor grade: TC-not reached, AC- 35.5 months, LCNEC- 10.1 months (Figure 6B). TC also had a significantly improved disease free survival compared to $\mathrm{AC}$ $(p=0.0168)$. There was also step-wise decrease in median overall survival with tumor grade. The median overall survival was not reached in TC and AC and both groups had significantly improved survival compared to LCNEC (median OS- 18.3 months, $\mathrm{p}<0.001$ ).

Multivariate survival analysis was performed with independent variables of age, gender, mitotic figures, and Ki-67 index, with both recurrence and death as end-
Table 2 Clinical characteristics

\begin{tabular}{|c|c|c|c|c|}
\hline & All tumors & TC & $A C$ & LCNEC \\
\hline $\mathrm{n}$ & 55 & 39 & 7 & 9 \\
\hline Mean age $\pm S D$ (yrs) & $60.8 \pm 11.2$ & $61.8 \pm 12.6$ & $61.5 \pm 6.5$ & $55.2 \pm 5.5$ \\
\hline Range (yrs) & $33.6-79.4$ & $33.6-79.4$ & $51.1-73.4$ & $47.5-61.6$ \\
\hline \multicolumn{5}{|l|}{ Sex } \\
\hline Females & $41(75 \%)$ & 31 (80\%) & $5(71 \%)$ & $5(56 \%)$ \\
\hline Males & $14(25 \%)$ & $8(20 \%)$ & $2(29 \%)$ & $4(44 \%)$ \\
\hline \multicolumn{5}{|l|}{ Race $^{\ddagger}$} \\
\hline White & 41 & 32 & 6 & 3 \\
\hline Black & 12 & 5 & 1 & 6 \\
\hline Other & 2 & 2 & 0 & 0 \\
\hline \multicolumn{5}{|l|}{ Smoking $\mathrm{hx}^{\dagger}$} \\
\hline Smoker & $27(59 \%)$ & $16(50 \%)$ & $2(40 \%)$ & $9(100 \%)$ \\
\hline Nonsmoker & $19(41 \%)$ & 16 (50\%) & $3(60 \%)$ & $0(0 \%)$ \\
\hline Data unavailable & 9 & 7 & 2 & 0 \\
\hline \multicolumn{5}{|l|}{ Location } \\
\hline Central & $46(84 \%)$ & $34(87 \%)$ & $6(86 \%)$ & $6(67 \%)$ \\
\hline Peripheral & $9(18 \%)$ & $5(13 \%)$ & $1(14 \%)$ & $3(33 \%)$ \\
\hline $\begin{array}{l}\text { Mean tumor } \\
\text { size } \pm S D(\mathrm{~cm})\end{array}$ & $2.2 \pm 1.5$ & $2.1 \pm 1.5$ & $2.7 \pm 1.9$ & $2.8 \pm 1.2$ \\
\hline Range $(\mathrm{cm})$ & $0.2-6.9$ & $0.2-6.9$ & $0.7-5.5$ & $0.4-4.5$ \\
\hline \multicolumn{5}{|l|}{ Tumor stage $(\mathrm{T})$} \\
\hline$T 1 a$ & 26 & 19 & 3 & 4 \\
\hline$T 1 b$ & 10 & 8 & 2 & 0 \\
\hline$T 2 a$ & 16 & 10 & 1 & 5 \\
\hline$T 2 b$ & 1 & 1 & 0 & 0 \\
\hline$T 3$ & 2 & 1 & 1 & 0 \\
\hline \multicolumn{5}{|l|}{ Nodal stage $(\mathrm{N})$} \\
\hline$N x$ & 1 & 0 & 0 & 1 \\
\hline No & 46 & 35 & 5 & 6 \\
\hline$N 1$ & 5 & 3 & 1 & 1 \\
\hline$N 2$ & 3 & 1 & 1 & 1 \\
\hline \multicolumn{5}{|l|}{ Metastatic stage (M) } \\
\hline MO & 53 & 39 & 6 & 8 \\
\hline M1 & 2 & 0 & 1 & 1 \\
\hline \multicolumn{5}{|l|}{ Procedure } \\
\hline Other & 2 & 1 & 1 & 0 \\
\hline Wedge & 14 & 5 & 2 & 7 \\
\hline Segmentectomy & 2 & 2 & 0 & 0 \\
\hline Lobectomy & 30 & 25 & 4 & 1 \\
\hline Bilobectomy & 4 & 4 & 0 & 0 \\
\hline Pneumonectomy & 3 & 2 & 0 & 1 \\
\hline
\end{tabular}

$\mathrm{AC}=$ atypical carcinoid; $\mathrm{TC}=$ typical carcinoid; $\mathrm{LCNEC}=$ large cell neuroendocrine carcinoma.

${ }^{\ddagger} p=0.0005$ Fisher's exact test, LCNEC vs. TC and AC, Whites vs. Blacks. ${ }^{+} \mathrm{p}=.005$, LCNEC vs. AC and TC. 


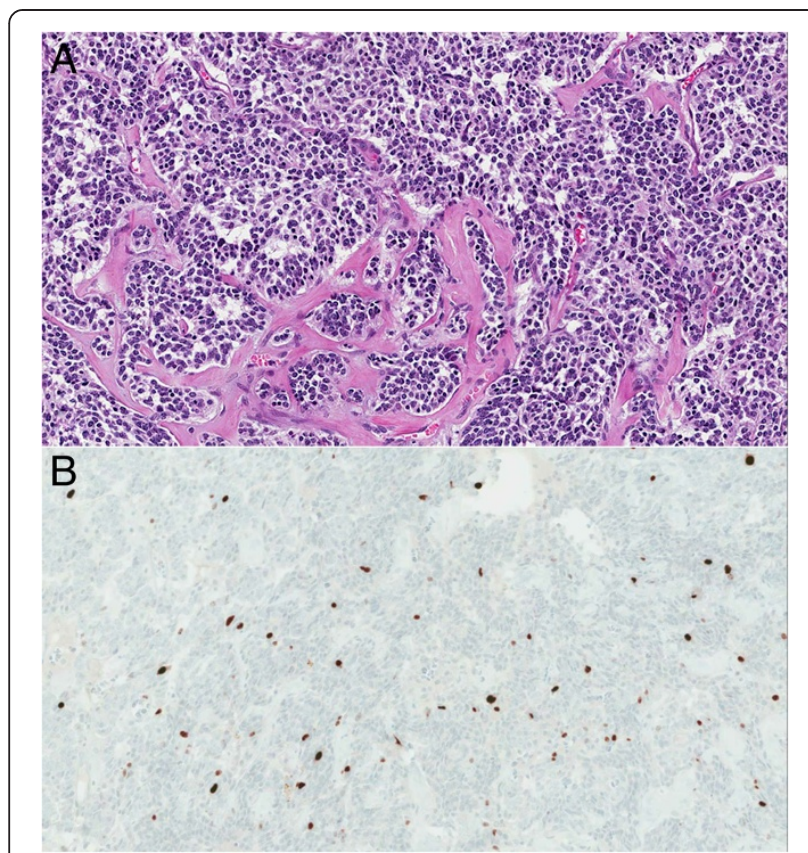

Figure 1 Typical carcinoid. A. Typical carcinoid tumor with osseous metaplasia showing anastomosing nests and cords. No mitoses or necrosis are identified. B. Ki-67, 20x magnification, showing $4.6 \%$ tumor positivity by digital image analysis.

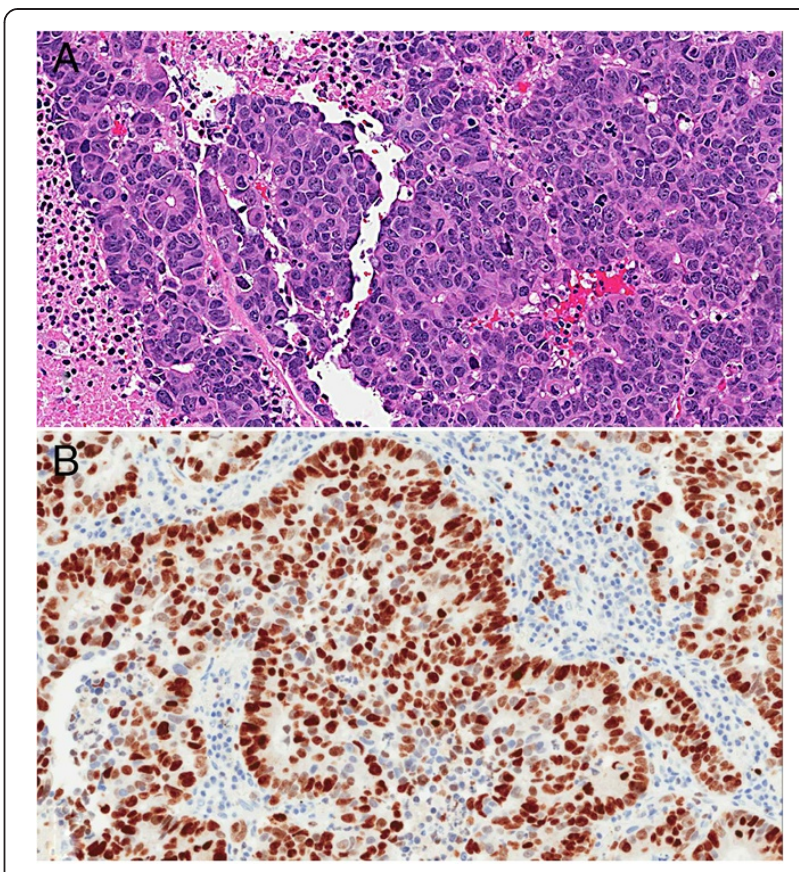

Figure 3 Large cell neuroendocrine carcinoma. A.H\&E, 20x magnification, large cell neuroendocrine tumor with solid and pseudoglandular growth patterns. Prominent nucleoli, geographic necrosis, and mitoses are readily evident. B. Ki-67, 20x magnification, showing $91.9 \%$ tumor positivity by digital image analysis.

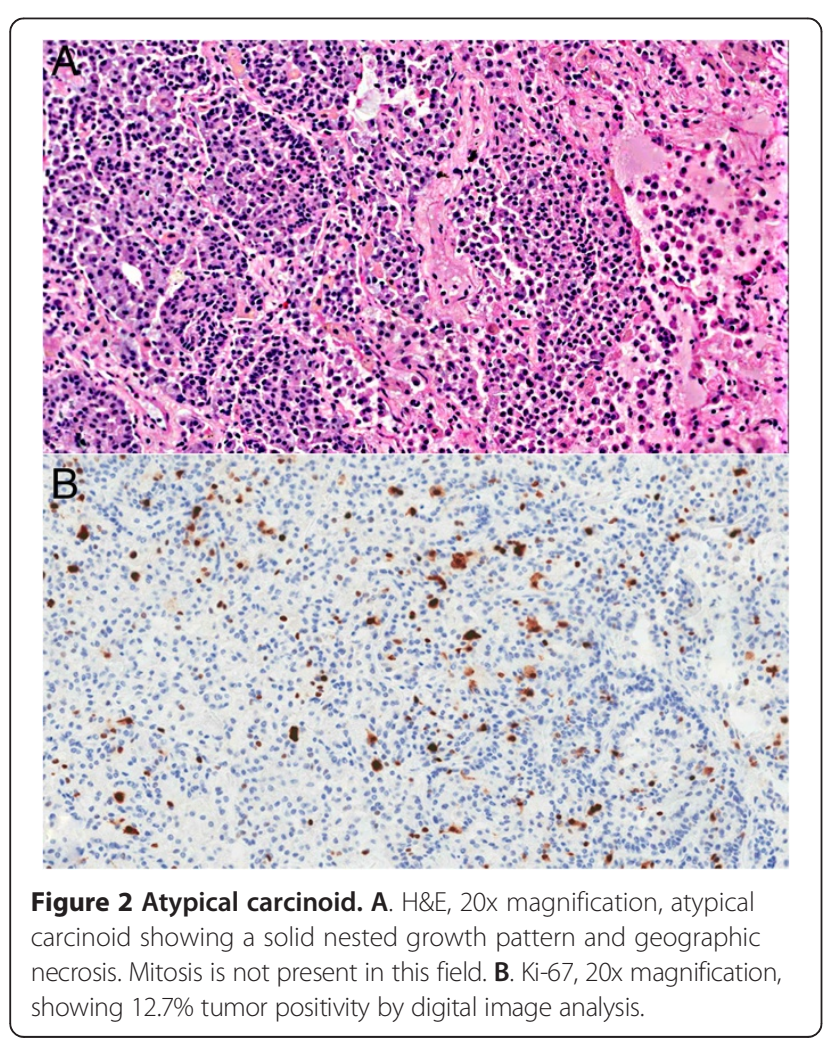

points. Ki-67 proliferative index was independently associated with death $(\mathrm{p}=.005)$ and recurrence $(\mathrm{p}=.02)$. In contrast, mitotic rate was not significantly associated with death $(\mathrm{p}=.07)$ or recurrence $(\mathrm{p}=0.4)$, nor was age (0.7 for both). Gender showed no significant association with survival or recurrence $(\mathrm{p}>0.05)$.

\section{Discussion}

There is consensus that small cell carcinomas of the lung, in addition to having a high mitotic rate, have a Ki-67 PI greater than 50\% [17-20]. However, there are fewer data on Ki-67 PI regarding pulmonary TC, AC and LCNEC. Most reported studies have used manual methodologies for calculating Ki-67 PI. In these studies, the mean Ki-67 PI for TC, AC, and LCNEC were 0.5$3.7 \%, 2.4-20 \%$, and $25-81 \%$ respectively $[11,12,19,21-24]$. There is no consensus threshold separating pulmonary AC from TC and LCNEC, with reported cutoff threshold ranging between $2.5 \%$ to $5 \%$ for $\mathrm{TC} \mathrm{v}$. AC, and a value of $30 \%$ for AC v. LCNEC $[9,11,12,19]$. In the gastrointestinal tract, corresponding cutoffs are $3 \%$ and $20 \%$, using both manual and automated Ki-67 methodology [25]; Yamaguchi, $2013 \# 41\}$, separating low from intermediate grade, and intermediate grade from high-grade neuroendocrine carcinomas, respectively. 


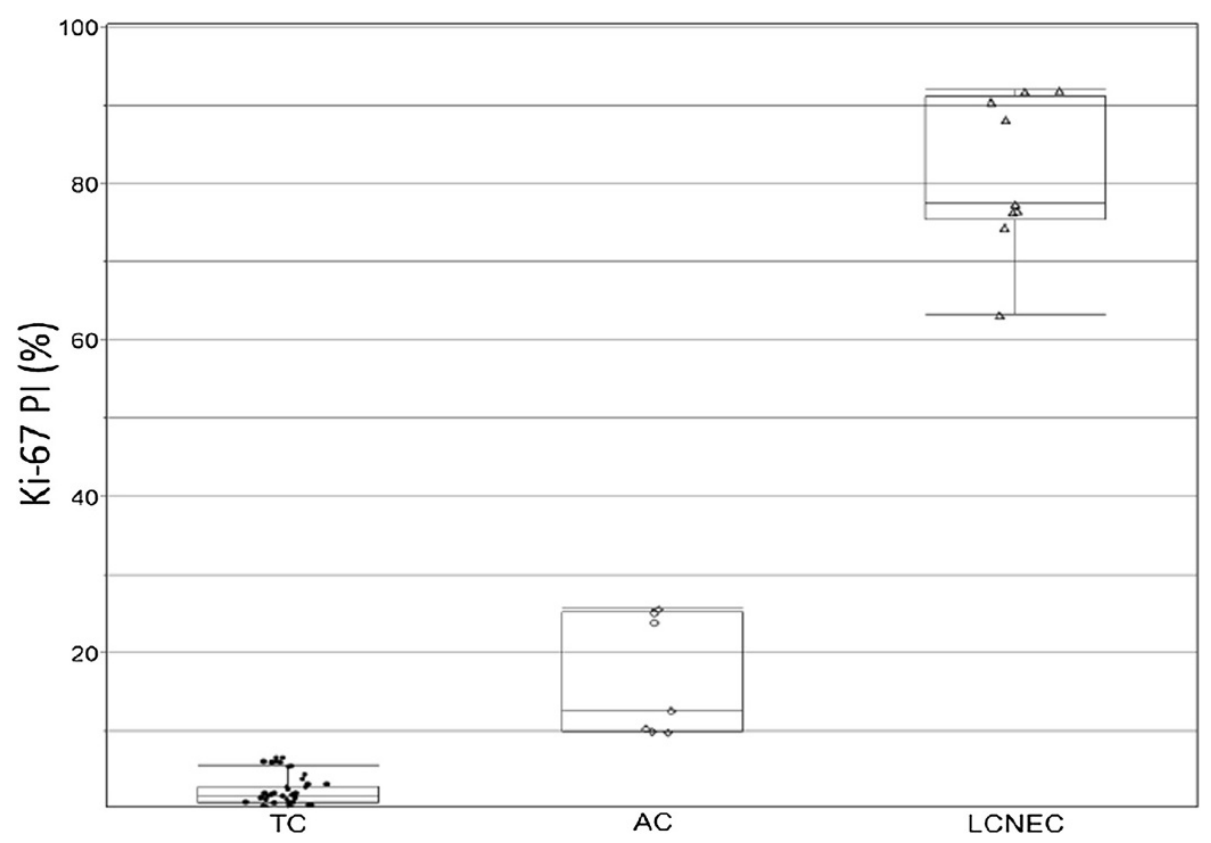

Figure 4 Ki-67 proliferative index by tumor type. Scatterplot of Ki67 index by histological type. Error bars represent standard deviation with mean. $\mathrm{TC}=$ typical carcinoid; $\mathrm{AC}=$ atypical carcinoid; $\mathrm{LCNEC}=$ large cell neuroendocrine carcinoma.

The current study is the first large quantitative study utilizing an established commercially available platform $\left(\right.$ Aperio $\left.^{\circ}\right)$ to quantify the Ki-67 PI of TC, AC, and LCNEC. Our reported mean Ki-67 PI for TC, AC, and LCNEC were $2.3 \%, 16.8 \%$, and $81.3 \%$ respectively. A cutoff of $7 \%$ reliably separated all TC and AC and a cutoff of $50 \%$ was a reliable cutoff between AC and LCNEC, with a wide interval of $\mathrm{Ki}-67 \mathrm{PI}$ in which $\mathrm{AC}$ and LCNEC did not overlap (30-60\%). A similar study on cytology smears, found a large range of Ki-67 PI (25-50\%) where low-grade neuroendocrine and high-grade neuroendocrine tumors did not overlap [17]. Our mean Ki-67 proliferative index across the spectrum of neuroendocrine tumors is somewhat higher than in most reported studies, possibly due to our differences in methodology in our using automatic cell counting - while this method has been previously validated against manual counting in breast cancers, it may have a lower threshold for counting weakly positive cells than some observers. Indeed, one of the strengths of automated quantitation of Ki-67 PI is elimination of interobserver variability in threshold for positivity. Our data for mean $\mathrm{Ki}-67$ is similar to a recent study by Watts et al., who reported a mean of $3.7 \%$ and $18.8 \%$ for TC and AC respectively [14]. However, a Ki-67

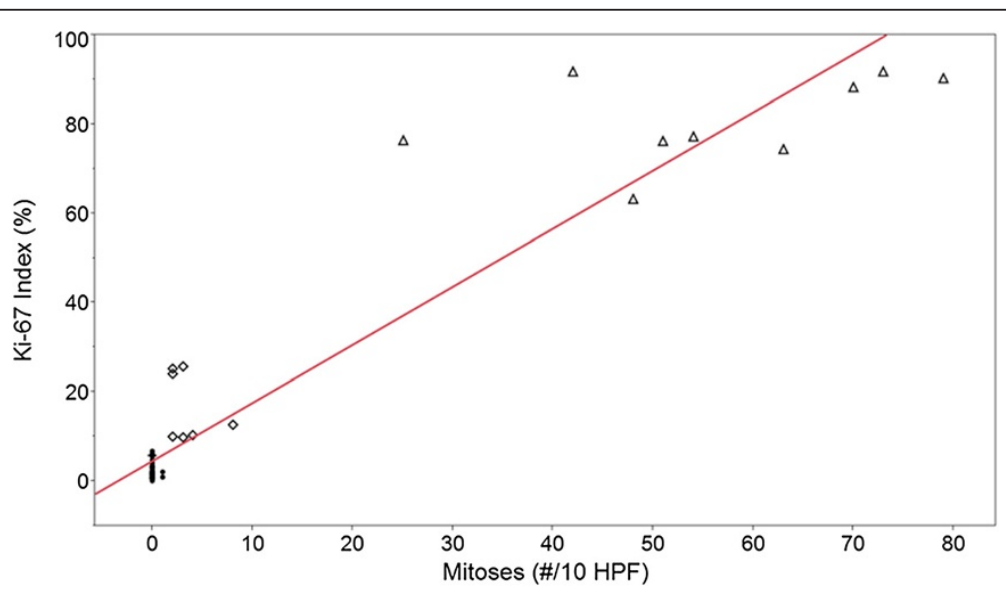

Figure 5 Ki-67 proliferative index versus mitoses. Scatterplot with simple linear regression of KI-67 PI vs. mitosis (\#/10 HPF). Dot- TC, Diamond-AC, Triangle- LCNEC. KI-67 PI (\%) = 4.59+ 1.30 (mitoses/\# 10HPF), $R^{2}=0.89, p<0.001$. 
Table 3 Reoccurrence and survival data

\begin{tabular}{|c|c|c|c|c|}
\hline & All tumors & TC & AC & LCNEC \\
\hline \multicolumn{5}{|l|}{ Clinical status at last $\mathrm{f} / \mathrm{u}$} \\
\hline Alive without recurrence & 35 & 30 & 5 & 0 \\
\hline Alive with recurrence & 2 & 0 & 1 & 1 \\
\hline Alive, unknown & 7 & 6 & 0 & 1 \\
\hline Died with disease & 8 & 0 & 1 & 7 \\
\hline Died of other causes & 2 & 2 & 0 & 0 \\
\hline Died, unknown cause & 1 & 1 & 0 & 0 \\
\hline Median disease free survival (months) ${ }^{\dagger}$ & NR & NR & 35.5 & 10.1 \\
\hline Hazard ratio & & $<0.01$ & 0.10 & 1.00 \\
\hline Confidence interval (95\%) & & - & $0.01-0.57$ & - \\
\hline$P$-value & - & $<0.0001$ & 0.0063 & - \\
\hline Mean DFS follow-up (months) & 20.2 & 21.9 & 21.9 & 12.0 \\
\hline Median survival (months) & NR & $N R$ & NR & 19.7 \\
\hline Hazard ratio & & 0.06 & 0.08 & 1.00 \\
\hline Confidence interval (95\%) & & $0.01-0.24$ & $0.00-0.54$ & - \\
\hline P-value & - & $<0.0001$ & 0.0070 & - \\
\hline Mean OS follow-up (months) & 29.6 & 31.4 & 34.3 & 18.3 \\
\hline
\end{tabular}

${ }^{\dagger} \mathrm{p}=0.0168, \mathrm{DFS}, \mathrm{TC}$ vs. AC.

$\mathrm{AC}=$ atypical carcinoid; $\mathrm{TC}=$ typical carcinoid $\mathrm{LCNEC}=$ large cell neuroendocrine carcinoma .

of up to $50 \%$ in two AC in two studies and up to $99 \%$ in one LCNEC have been reported $[14,24,26]$. In an older study by Costes et al., a Ki-67 of $0-3.0 \%$ for TC and 0-6.1\% for AC was reported [9].

Determination of Ki-67 PI may be useful in small biopsies or in cytological specimens where diagnostic tissue is limited for morphologic and proliferative activity assessment due to small sample size and or crush artifact. In these samples, a carcinoid tumor maybe over-diagnosed as high-grade neuroendocrine tumor or vice versa $[18,20]$. Although this study was limited to resection specimens, and the proposed cutoffs require validation before use in small biopsy or cell block specimens, previous studies seem to support the value of Ki-67 PI in such specimens. Watanabe et al. found no mitotic figures in 7 of 38 small biopsies of LCNECs, and 11 of 38 small biopsies had inadequate tumor volume for mitotic count $(<10 \mathrm{HPF})$; nevertheless, a Ki-67 index could adequately be assessed in all biopsies, and it was found to be in a range of $42-99 \%$ [24]. Furthermore, at least one study has shown Ki-67 PI is a reliable test in inter-observer agreement between $\mathrm{TC}$ and AC [3]. Accurate distinction between a high grade and low to intermediate grade neuroendocrine tumor is important because of different biological behaviors, including overall survival and disease free survival, among TC, AC, and high-grade neuroendocrine tumors $[7,15,21]$.

Digital image analysis of Ki-67 PI has been shown to have improved diagnostic accuracy compared to visual estimation for neuroendocrine tumors of the gastrointestinal tract [27]. Tang et al. found that visual estimation is subject to both low intra-observer and inter-observer agreement for grading of gastrointestinal neuroendocrine tumors. Compared to manual counting (of all individual tumor cells), automated counting showed excellent concordance (98\%) [27]. The usefulness of automated Ki-67 in predicting gastrointestinal neuroendocrine tumor has been clinically validated at least in one study [28].

The potential technical limitations of automated analysis of Ki-67 PI are: a requirement for in-house validation of the method against manual cell count; counting a sufficient number of tumor cells to avoid misrepresentation of Ki-67 from intra-tumoral variability; and methods to exclude counting on non-tumor mitotic activity. Regarding validation, the College of American Pathologists has issued guidance on validation of quantitative assays for estrogen receptor and progesterone receptor that are helpful in establishing standards for clinical validation [16]. Regarding cell counts, the WHO recommends counting at least 500 cells for grading neuroendocrine tumors of the GI tract; however, we tried to limit intratumoral variability by using a much higher threshold of 2000 tumor cells across at least 3 distinct manually annotated representative tumor fields. Automated image analysis renders scoring a large number of cells a trivial additional burden. The last issue, exclusion of non-tumor cells is the most complicated. The combination of manual selection of tumor fields with few non-tumor cells, and use of a counting system that uses size and/or other 

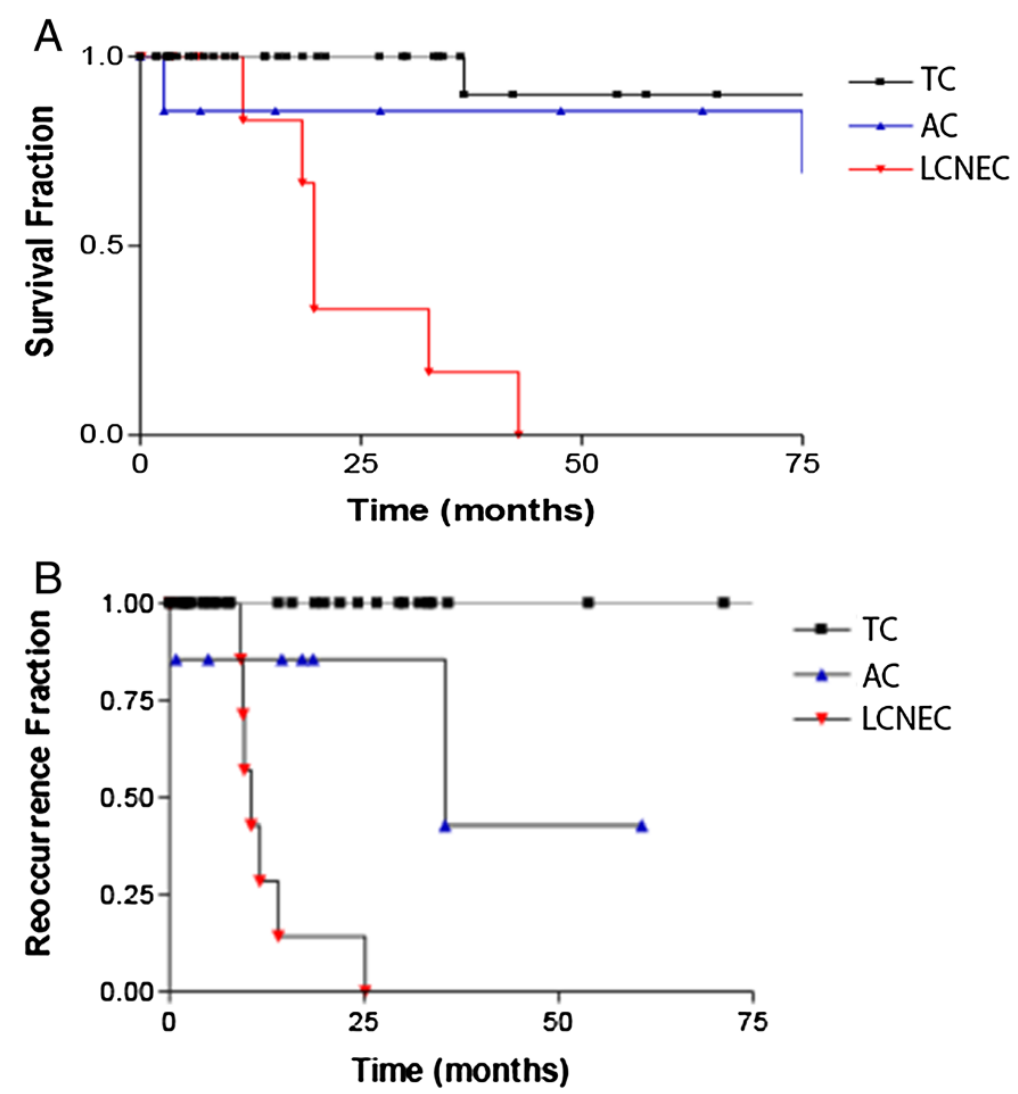

Figure 6 Overall and disease free survival by tumor type. A: Kaplan-Meier Curves, overall survival by histological type. Although there is a marked difference between LCNEC and carcinoid, there is no difference between typical and atypical carcinoid. B: Kaplan-Meier Curves, disease free survival by histological type. The recurrence rate for AC is intermediate between TC and LCNEC.

criteria to exclude intratumoral inflammatory cells is necessary to overcome this problem.

The current study reports similar results to previously published data on overall survival between LCNEC and carcinoid tumors. However, we did not find a difference in overall survival between $\mathrm{TC}$ and $\mathrm{AC}$, probably due to relatively low number of $\mathrm{AC}(\mathrm{n}=7)$, a limitation in our study. One patient with $\mathrm{AC}$ in our study was unusual, in that death occurred 2.5 months after diagnosis, but this patient had delayed medical treatment and was initially diagnosed with distant metastasis. Our follow-up data did show a marked biologic difference between LCNEC and carcinoid tumors; all LCNEC with available followup data (8/8) recurred with a poor median overall survival of 19.7 months. There was a significant stepwise decrease in DFS with tumor grade, similar to previous studies; the reported 5 year survival rates are $87-97 \%$, 56$78 \%$, and $15 \%-40 \%$, respectively for TC, AC, and LCNEC $[6-8,12,21,29,30]$. We found a strong association between black race, smoking and LCNEC, and in the latter, a traditional risk factor shared with small cell carcinoma [6,7]. In contrast to other series showing no gender predilection
[1], we showed a predominance of women (3:1 ratio) for $\mathrm{AC}$ and TC.

\section{Conclusion}

The current study identified cutoffs that reliably separated surgically resected endocrine tumors of the lung by Ki-67 proliferative indexing using automated digital image analysis. With our system, which has been validated for prognostication in breast cancers, a cutoff of 7\% separated AC from TC, and there was a wide area (between 30 and 60\%) that separated LNEC from AC.

\section{Competing interests}

The authors declare that they have no competing interests.

\section{Authors' contributions}

SZL provided statistical analysis, literature research, histologic review and drafted the manuscript. PNS finalized manuscript draft and assisted in case review. LG performed automated quantitation of proliferative index. BAA provided immunohistochemical staining. NS provided cases and follow up data with RD. APB conceived the project, oversaw data analysis, and reviewed all histologic analysis. All authors read and approved the final manuscript. 
Received: 5 June 2014 Accepted: 23 August 2014

Published online: 16 October 2014

\section{References}

1. Travis WD: Lung tumours with neuroendocrine differentiation. Eur J Cancer 2009, 45(Suppl 1):251-266.

2. Kayser K, Kayser C, Rahn W, Bovin NV, Gabius HJ: Carcinoid tumors of the lung: immuno- and ligandohistochemistry, analysis of integrated optical density, syntactic structure analysis, clinical data, and prognosis of patients treated surgically. J Surg Oncol 1996, 63:99-106.

3. Warth A, Fink L, Fisseler-Eckhoff A, Jonigk D, Keller M, Ott G, Rieker RJ, Sinn P, Soder S, Soltermann A, Willenbrock K, Weichert W: Interobserver agreement of proliferation index (Ki-67) outperforms mitotic count in pulmonary carcinoids. Virchows Arch 2013, 462:507-513.

4. Kayser K, Richter B, Stryciak R, Gabius HJ: Parameters derived from integrated nuclear fluorescence, syntactic structure analysis, and vascularization in human lung carcinomas. Anal Cell Pathol 1997, 15:73-83.

5. Kim Y, Choi YD, Kim BJ, Oh IJ, Song SY, Nam JH, Park CS: Multiple peripheral typical carcinoid tumors of the lung: associated with sclerosing hemangiomas. Diagn Pathol 2013, 8:97.

6. Asamura H, Kameya T, Matsuno Y, Noguchi M, Tada H, Ishikawa Y, Yokose T, Jiang SX, Inoue T, Nakagawa K, Tajima K, Nagai K: Neuroendocrine neoplasms of the lung: a prognostic spectrum. J Clin Oncol 2006, 24:70-76.

7. Travis WD, Rush W, Flieder DB, Fleming MV, Gal AA, Koss MN: Survival analysis of 200 pulmonary neuroendocrine tumors with clarification of criteria for atypical carcinoid and its separation from typical carcinoid. Am J Surg Pathol 1998, 22:934-944.

8. Beasley MB, Thunnissen FB, Brambilla E, Hasleton P, Steele R, Hammar SP, Colby TV, Sheppard M, Shimosato Y, Koss MN, Falk R, Travis WD: Pulmonary atypical carcinoid: predictors of survival in 106 cases. Hum Pathol 2000, 31:1255-1265.

9. Costes V, Marty-Ane C, Picot MC, Serre I, Pujol JL, Mary H, Baldet P: Typical and atypical bronchopulmonary carcinoid tumors: a clinicopathologic and KI-67-labeling study. Hum Pathol 1995, 26:740-745.

10. Faggiano A, Mansueto G, Ferolla P, Milone F, de Caro ML e B, Lombardi G, Colao A, De Rosa G: Diagnostic and prognostic implications of the World Health Organization classification of neuroendocrine tumors. J Endocrinol Invest 2008, 31:216-223.

11. Grimaldi F, Muser D, Beltrami CA, Machin P, Morelli A, Pizzolitto S, Talmassons G, Marciello F, Colao AA, Monaco R, Monaco G, Faggiano A: Partitioning of bronchopulmonary carcinoids in two different prognostic categories by ki-67 score. Front Endocrinol (Lausanne) 2011, 2:20.

12. Rugge M, Fassan M, Clemente R, Rizzardi G, Giacomelli L, Pennelli G, Mescoli C, Segat D, Rea F: Bronchopulmonary carcinoid: phenotype and long-term outcome in a single-institution series of Italian patients. Clin Cancer Res 2008, 14:149-154.

13. Skov BG, Holm B, Erreboe A, Skov T, Mellemgaard A: ERCC1 and Ki67 in small cell lung carcinoma and other neuroendocrine tumors of the lung: distribution and impact on survival. J Thorac Oncol 2010, 5:453-459.

14. Walts $A E$, Ines $D$, Marchevsky AM: Limited role of Ki-67 proliferative index in predicting overall short-term survival in patients with typical and atypical pulmonary carcinoid tumors. Mod Pathol 2012, 25:1258-1264.

15. Travis WD: Advances in neuroendocrine lung tumors. Ann Oncol 2010, 21(Suppl 7):vii65-vii71.

16. Fitzgibbons PL, Murphy DA, Hammond ME, Allred DC, Valenstein PN: Recommendations for validating estrogen and progesterone receptor immunohistochemistry assays. Arch Pathol Lab Med 2010, 134:930-935.

17. Lin O, Olgac S, Green I, Zakowski MF, Klimstra DS: Immunohistochemical staining of cytologic smears with MIB-1 helps distinguish low-grade from high-grade neuroendocrine neoplasms. Am J Clin Pathol 2003, 120:209-216.

18. Zheng G, Ettinger DS, Maleki Z: Utility of the quantitative Ki-67 proliferation index and CD56 together in the cytologic diagnosis of small cell lung carcinoma and other lung neuroendocrine tumors. Acta Cytol 2013, 57:281-290.

19. Pelosi G, Rindi G, Travis WD, Papotti M: Ki-67 antigen in lung neuroendocrine tumors: unraveling a role in clinical practice. $J$ Thorac Oncol 2014, 9:273-284.

20. Pelosi G, Rodriguez J, Viale G, Rosai J: Typical and atypical pulmonary carcinoid tumor overdiagnosed as small-cell carcinoma on biopsy specimens: a major pitfall in the management of lung cancer patients. Am J Surg Pathol 2005, 29:179-187.

21. Rekhtman N: Neuroendocrine tumors of the lung: an update. Arch Pathol Lab Med 2010, 134:1628-1638.

22. Laitinen KL, Soini Y, Mattila J, Paakko P: Atypical bronchopulmonary carcinoids show a tendency toward increased apoptotic and proliferative activity. Cancer 2000, 88:1590-1598.

23. Iyoda A, Hiroshima K, Moriya Y, Mizobuchi T, Otsuji M, Sekine Y, Shibuya K, lizasa T, Saitoh Y, Fujisawa T: Pulmonary large cell neuroendocrine carcinoma demonstrates high proliferative activity. Ann Thorac Surg 2004, 77:1891-1895. discussion 1895.

24. Watanabe R, Ito I, Kenmotsu H, Endo M, Yamamoto N, Ohde Y, Kondo H, Nakajima T, Kameya T: Large cell neuroendocrine carcinoma of the lung: is it possible to diagnose from biopsy specimens? Jpn J Clin Oncol 2013, 43:294-304.

25. Jamali $M$, Chetty R: Predicting prognosis in gastroentero-pancreatic neuroendocrine tumors: an overview and the value of Ki-67 immunostaining. Endocr Pathol 2008, 19:282-288.

26. Al-Khafaji B, Noffsinger AE, Miller MA, DeVoe G, Stemmermann GN, Fenoglio-Preiser C: Immunohistologic analysis of gastrointestinal and pulmonary carcinoid tumors. Hum Pathol 1998, 29:992-999.

27. Tang LH, Gonen M, Hedvat C, Modlin IM, Klimstra DS: Objective quantification of the Ki67 proliferative index in neuroendocrine tumors of the gastroenteropancreatic system: a comparison of digital image analysis with manual methods. Am J Surg Pathol 2012, 36:1761-1770.

28. Yamaguchi T, Fau FT, Tomita S, Fau TS, Ichikawa K, Mitomi H, Ohno K, Shida Y, Kato H: Clinical validation of the gastrointestinal NET grading system: Ki67 index. Diagn Pathol 2013, 8:65. LID - 10.1186/1746-1596-8-65 [doi].

29. Thomas CF Jr, Tazelaar HD, Jett JR: Typical and atypical pulmonary carcinoids : outcome in patients presenting with regional lymph node involvement. Chest 2001, 119:1143-1150.

30. Garcia-Yuste M, Matilla JM, Cueto A, Paniagua JM, Ramos G, Canizares MA, Muguruza I: Typical and atypical carcinoid tumours: analysis of the experience of the Spanish Multi-centric Study of Neuroendocrine Tumours of the Lung. Eur J Cardiothorac Surg 2007, 31:192-197.

doi:10.1186/s13000-014-0174-z

Cite this article as: Liu et al: Automated quantification of Ki-67 proliferative index of excised neuroendocrine tumors of the lung. Diagnostic Pathology 2014 19:174.

\section{Submit your next manuscript to BioMed Central and take full advantage of:}

- Convenient online submission

- Thorough peer review

- No space constraints or color figure charges

- Immediate publication on acceptance

- Inclusion in PubMed, CAS, Scopus and Google Scholar

- Research which is freely available for redistribution 